Document downloaded from:

http://hdl.handle.net/10251/59958

This paper must be cited as:

Echeverria Villar, JA.; Martínez-Román, J.; Serrano Iribarnegaray, L. (2012). Transient harmonic torques in induction machines: measurement and impact on motor performance. Electrical Engineering. 94(2):67-80. doi:10.1007/s00202-011-0216-4.

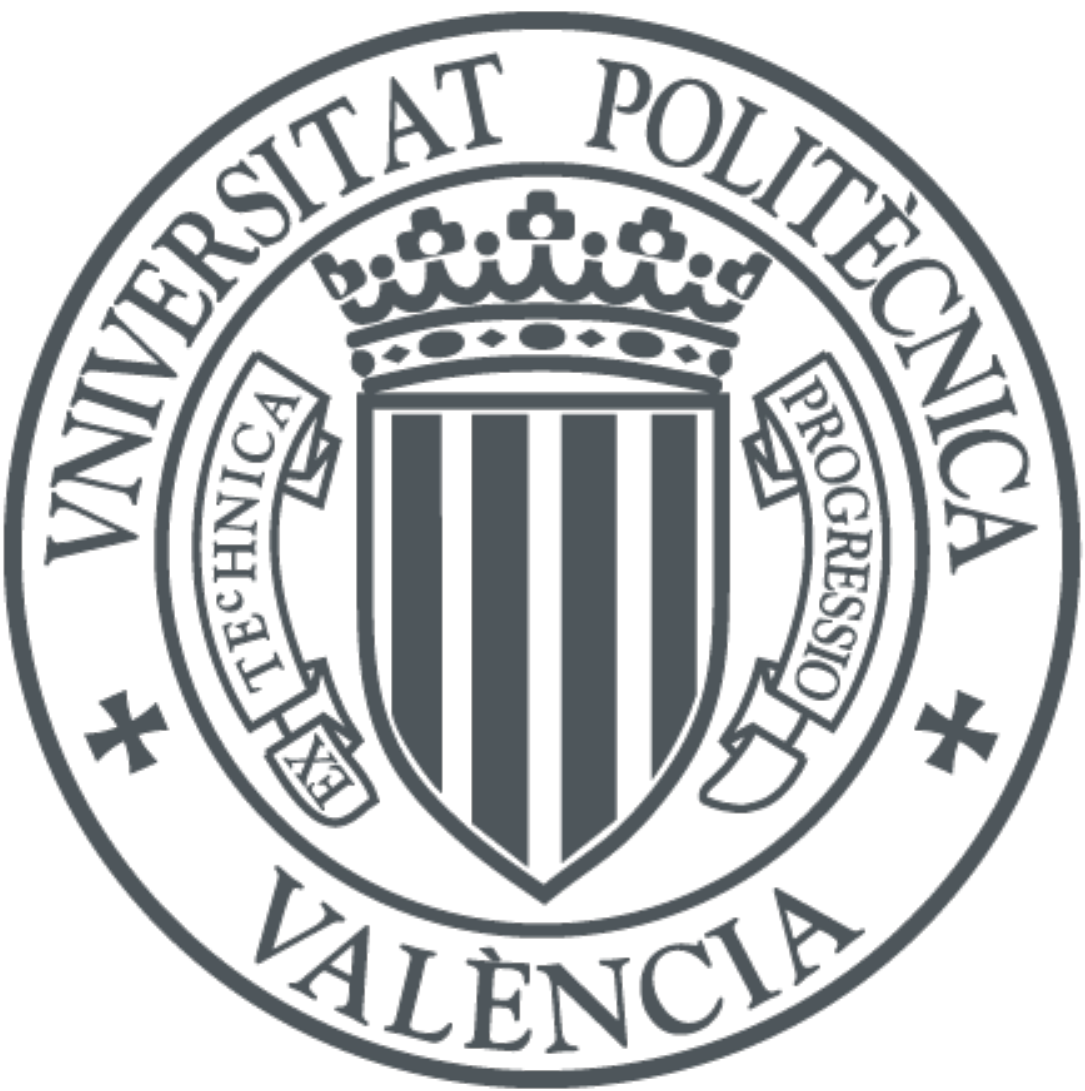

The final publication is available at

http://dx.doi.org/10.1007/s00202-011-0216-4

Copyright Springer Verlag (Germany)

Additional Information 


\section{Transient harmonic torques in induction machines: measurement and impact on motor performance}

\author{
José-Antonio Echeverría-Villar \\ Javier Martínez-Román \\ Luis Serrano-Iribarnegaray
}

\begin{abstract}
This paper focuses on the measurement of transient torques produced by the field harmonics in three phase squirrel cage motors and on the assessment of the operating conditions under which these torques might become significant. The paper presents first a model of the induction machine with any stator and rotor phase number and configuration, fed by arbitrary voltage waveforms and taking into account the space harmonics. Then, very much attention is paid to a reliable model validation against actual transient torques measurements. In this sense, the actual and great difficulties of measuring pulsating electromagnetic torques of hundreds of hertz are brought into light, the possible measurement techniques are critically reviewed and the solution chosen is discussed.
\end{abstract} Once the model accuracy has been experimentally confirmed, it is used to carry out a systematic plan of more than 250 simulations under clearly distinct operating conditions on five different motors. The analysis of these simulations yields a main practical conclusion: field harmonics may have (depending on the motor structure) a significant impact on electromagnetic torque, but only during transients characterized by high instantaneous frequencies of the rotor currents. For low slip transients their impact is negligible. This conclusion is also theoretically justified in the paper.

Keywords Field harmonic torques, Induction machines, Space phasors, Torque measurement.

\section{INTRODUCTION}

Studies on transient behavior of induction motors with space harmonics were already carried out in the past century using different ways and almost always trying to resort to some kind of transformations (mainly the symmetrical component transformation) [1]-[5].

Initially the main reason to include field harmonics in the motor analysis was the fact that, for specific stator and rotor slots combinations, it was realized that harmonic torques could seriously impair, or even prevent, the motor start up [6]. Later on, apart from other drawbacks (like noise coming from radial force waves, increase of the additional losses, etc. see [7,8]) engineers became aware that harmonic fields effects during transients result in fast oscillations 
of the electromagnetic torque that are superposed to the fundamental dynamic torque. This last aspect of the harmonic fields (their impact on transient torques) is the main topic addressed in this paper.

The pulsating torques are a source of noise and vibrations and can be particularly dangerous if their frequency is close to the mechanical natural frequency. Due to this and to all of the other reasons just mentioned, no wonder that harmonic torques have been considered, almost universally, to be detrimental and harmful, which is true for three phase induction motors. However, it is known today that in induction motors with a number of stator phases greater than three, it is possible to make use of certain field harmonics (the greater the phase number, the higher the number of harmonics) in order to increase the total useful motor torque [9]. It is important to keep in mind this potentially beneficial effect of some space harmonics in converter - fed multiphase machines.

Due to this last fact, the model in this paper has been developed to analyze machines with any stator and rotor phase number, since, from an operational and conceptual viewpoint, the structure of the equations is the same regardless of the stator having three or more phases (Notice that actually the squirrel cage winding already constitutes a polyphase winding). The deduction process of the equations by means of space phasors is briefly presented in chapter II.

An experimental validation of a machine model whose main aim is the simulation of transient torques due to space harmonics is a very serious challenge. That is why very much attention is thereafter paid to an accurate and reliable experimental model validation. Such a validation requires a direct comparison between harmonic torque simulations and measurements. In this sense, the actual and great difficulties of measuring pulsating electromagnetic torques of hundreds of hertz are brought into light, the possible measurements techniques are critically reviewed and the option chosen is deeply discussed and justified. This is done in chapter III. It must be emphasized that this topic has been almost completely ignored in the technical literature.

On the other hand, most of the papers on transient analysis of three phase induction machines with space harmonics share a rather similar structure. First they introduce a more or less simplified system of differential equations, usually by means of some kind of transformation. Thereafter they compute that model in a few specific situations (often with a considerable limitation in the number of harmonics considered). It seems clear that hardly any general conclusion on the impact of field harmonics on the motor torque during transients can be obtained this way. By contrast, the work in this paper has been built on the analysis of 
more than 250 simulations under clearly distinct operating conditions of five different motors. This analysis is carried out in chapter IV. It yields a first and general validity conclusion with practical relevance which reads: for motor operation modes with low rotor current instantaneous frequencies (usually associated to low slip operation modes), the field harmonics effect on the transient electromagnetic torque of three phase squirrel cage motors is always negligible. In other words, as a general rule, space harmonics can become important as to the transient electric torque only at high slips (like during direct on-line start-up, unplugging, injection braking, rather long dropouts, etc). This conclusion, which was initially observed, without exception, in the simulations, is thereafter also theoretically justified in a qualitative manner in chapter $\mathrm{V}$. To this end, the space phasor concept turns out to be a very useful tool.

\section{Model Development}

The simplified hypotheses are as follows:

- Ideal magnetic circuit.

- Constant air-gap of negligible width.

- Symmetrical polyphase windings in stator and rotor with constant parameters.

- The leakage flux linkage of a phase is proportional to the phase current. Any phase of an electrical machine produces a current sheet space wave that can be split into space harmonics. Known the structure of phase $A$ and its current, $i_{A}(t)$, the magnitude and position of the space harmonic of relative order $h$ (absolute order $v=h \cdot p$ ) of its current sheet is fully characterized by the space phasor (see equation A.3 in appendix):

$$
\overline{a_{h^{*} p, A}}=\frac{2 Z_{A}}{\pi D} i_{A}(t) \overline{\xi_{h \cdot p, A}}
$$

The complex constant $\xi_{h p, A}$ is the complex winding factor of the phase. Its module includes both the distribution and the pitch factors as well as the slot factor (effect of considering a linear change of MMF along the slot opening instead of an abrupt change at the middle of the slot). Complex variable $\boldsymbol{a}_{h \cdot p, A}$ is known as the harmonic current sheet space phasor of phase A. $\mathrm{Z}$ is the phase conductor number and $\mathrm{D}$ the air gap diameter.

The current sheet space phasor of a polyphase winding is simply the sum of the space phasors of all of its phases. Let it be a machine with $p$ pair of poles with a symmetric polyphase winding in stator or rotor, with $m_{w n d g}$ symmetrical phases. Let's choose as abscise axis the symmetry axis of first phase, and let's define as $\xi_{h, w n d g}$ the winding factor of relative order $h$ of this first phase. Due to winding symmetry, the phase in the generic position " $k$ " reproduces the configuration of phase 1 but with a $2 \pi \cdot(k$ $1) /\left(p \cdot m_{w n d g}\right)$ angular displacement in the machine, and therefore its winding factor in the complex phasorial domain is : 
$\left(\overline{\xi_{h p}}\right)_{\text {phase } k}=\left(\overline{\xi_{h p}}\right)_{\text {phase } 1} e^{j h p(k-1) \frac{2 \pi}{p \cdot m_{\text {vand g }}}}=\overline{\xi_{h p, \text { wndg }}} e^{j h(k-1) \frac{2 \pi}{m_{\text {vand }}}}$

Thus, the space harmonic of relative order $\mathrm{h}$ of the total current sheet produced by an m-phase symmetric winding fed by arbitrary currents $i_{1}(t), i_{2}(t), \ldots . . i_{m}(t)$, will be characterized by its space phasor, the expression of which, deduced immediately from (1) and (2), is:

$\overrightarrow{a_{h p, w n d g}}=\frac{2 Z_{w n d g}}{\pi D} \overline{\xi_{h p, w n d g}} \sum_{k=1}^{m_{w n d g}} i_{k}(t) e^{j h(k-1) \frac{2 \pi}{m_{w n d g}}}$

For practical reasons, instead of the current sheet space phasor in (3) it is often better in the machine electrical equations to make use of the so called current space phasor, defined as:

$\overline{i_{h p, w n d g}}=\frac{\overline{\xi_{h p, w n d g}}}{\left|\overline{\xi_{h p, w n d g}}\right|} \frac{2}{m_{\text {wndg }}} \sum_{k=1}^{m_{\text {wndg }}} i_{k}(t) e^{j h(k-1) \frac{2 \pi}{m_{w n d g}}}$

Notice that both phasors only differ by a constant and therefore they represent (at different scales) the same space quantity. In the particular and very practical case of the fundamental current sheet wave $(h=1)$ of a three phase winding, it follows from (4):

$\overrightarrow{i_{1, w n d g}}=\frac{2}{3}\left(i_{R}(t)+i_{S}(t) e^{j \frac{2 \pi}{3}}+i_{R}(t) e^{j \frac{4 \pi}{3}}\right)$

Expression (5) was first introduced by Park [10] and its physical interpretation was given later on by Kron who indicated that (5) represented the linear current density wave of the three phase winding (page 354 in [10]). The Fourier expansion of the current sheet is a key step in the analysis of polyphase machines with field harmonics, as emphasized and carried out in chapter 11 of [1]. Formula (4) is a generalization of (5) and constitutes an alternative and easy way to characterize the current sheet harmonics of windings with arbitrary number of phases.

The stator and rotor current sheets of the same order, $h$, combine to give the machine current sheet of order $h$, whose expression, in stator coordinates, is:

$$
\begin{aligned}
& \overrightarrow{a_{h p, m a c h}}=\overrightarrow{a_{h p, s t r}}+\left(\overrightarrow{a_{h p, r o t}}\right) e^{j h p \lambda(t)}= \\
& =\frac{2 Z_{s t r}}{\pi D} \overline{\xi_{h p, s t r}} \sum_{y=1}^{m_{s t r}} i_{y}(t) e^{j h(y-1) \frac{2 \pi}{m_{s t r}}}+ \\
& +\left(\frac{2 Z_{r o t}}{\pi D} \overrightarrow{\xi_{h p, r o t}} \sum_{x=1}^{m_{r o t}} i_{x}(t) e^{j h(x-1) \frac{2 \pi}{m_{r o t}}}\right) e^{j h p \lambda(t)}
\end{aligned}
$$

where $\lambda(t)$ is the mechanical angle between stator and rotor. It is again underlined that the phase currents may be arbitrary.

Any sinusoidal machine current sheet wave (6) produces an air gap sinusoidal machine induction wave with the same number of poles, $\mathrm{hp}$. The air gap flux linkage of any stator phase, "y", due exclusively to this induction wave is (see appendix):

$$
\begin{gathered}
\Psi_{y, h}(t)=\frac{\overline{\xi_{h p, s t r}}}{\left|\overline{\xi_{h p, s t r}}\right|} \operatorname{Real}\left[\left(\frac{m_{s t r}}{2} L_{h, s t r} \overline{i_{h, s t r}}+\right.\right. \\
\left.\left.+\frac{m_{r o t}}{2} L_{h, \text { mut }} \overline{i_{h, r o t}} e^{j h p \lambda(t)}\right) e^{-j(y-1) \frac{2 \pi}{m_{s t r}}}\right]
\end{gathered}
$$

For each rotor phase, “ $x$ ”, we get an analogous equation, after translating the current phasors to the rotor system. 


$$
\begin{aligned}
\Psi_{x, h}(t)= & \frac{\overline{\xi_{h p, r o t}}}{\left|\overline{\xi_{h p, r o t}}\right|} \operatorname{Real}\left[\left(\frac{m_{s t r}}{2} L_{h, \text { mut. }} \overline{i_{h, \text { str }}} e^{-j h p \lambda(t)}+\right.\right. \\
& \left.\left.+\frac{m_{\text {rot }}}{2} L_{h, \text { rot }} \overline{i_{h, \text { rot }}}\right) e^{-j(x-1) \frac{2 \pi}{m_{\text {rot }}}}\right]
\end{aligned}
$$

In (7) and (8) the magnetizing inductances of a stator $(L h, s t r)$ or rotor $(L h, r o t)$ phase and the maximum mutual inductance stator-rotor $\left(L_{h, m u t}\right)$ for the induction space wave of order $h$ are given by the well - known expressions (see appendix):

$$
L_{h, s t r}=\frac{\mu_{0} l D}{2 \pi \delta}\left(\frac{Z_{s t r} \xi_{h, s t r}}{p h}\right)^{2} ; L_{h, \text { rot }}=\frac{\mu_{0} l D}{2 \pi \delta}\left(\frac{Z_{r o t} \xi_{h, r o t}}{p h}\right)^{2}
$$

$$
L_{h, \text { mut }}=\xi_{h, \gamma} \sqrt{L_{h, s t r} L_{h, r o t}}
$$

Notice that (7) and (8) are valid also for machines with skewed conductors in which skew effects are accounted for by multiplying the mutual inductance without skew by the classical skewing factor, $\xi_{h, \gamma}$, as shown in(10).

From (7) and (8), the total flux linkages of a stator (" $y$ ") or rotor (" $x$ ") phase are given by:

$$
\begin{aligned}
& \Psi_{y}(t)=\left(\sum_{h=1}^{h_{\max }} \Psi_{y, h}(t)\right)+L_{\sigma, s t r} i_{y}(t) \\
& \Psi_{x}(t)=\left(\sum_{h=1}^{h_{\max }} \Psi_{x, h}(t)\right)+L_{\sigma, r o t} i_{x}(t)
\end{aligned}
$$

The leakage inductances of stator and rotor in (11) only include end winding and slot leakage inductance

$$
L_{\sigma}=L_{\sigma, \text { slot }}+L_{\sigma, \text { end winding }}
$$

The electric equation of any phase $A$ is:

$u_{A}(t)=R \cdot i_{A}(t)+\frac{d \Psi_{A}(t)}{d t}(13)$

If the phase voltages are known, particularizing (13) to every stator and rotor phase after having replaced in it the corresponding values given by(11), (8), (7) and (4) , we get a system of $\left(m_{e s t}+m_{r o t}\right)$ independent equations in which the unknowns are the $\left(m_{e s t}+\right.$ $\left.m_{r o t}\right)$ phase currents plus the mechanical angle, $\lambda(t)$. The additional relation required is provided by the mechanical equation (which must include, of course, the instantaneous torque produced by the fundamental and all the harmonic space waves considered):

$$
\begin{gathered}
T_{\text {elec }}(t)-T_{\text {load }}=J \frac{d^{2} \lambda(t)}{d t^{2}} \\
T_{\text {elec }}(t)=\frac{m_{\text {est }} m_{\text {rot }}}{4} \sum_{h=1}^{h_{\max }} h p L_{h, m .}\left(\overrightarrow{i_{h, \text { rot }}} e^{j h p \lambda(t)} \times \overrightarrow{i_{h, \text { est }}}\right)
\end{gathered}
$$

A computer program has been developed to solve directly (14) as well as (13) applied to all of the machine phases. The maximum harmonic order, $h_{\max }$, of the space waves participating in the torque production can be freely set in the program. Naturally as $h_{\max }$, decreases the leakage inductance in (12) is increased in due manner. In particular, for $h_{\max }=$ 1 , it turns out to be the case developed in basic books on classic theory, and equation (12) then becomes:

$$
L_{\sigma}=L_{\sigma, \text { slot }}+L_{\sigma, \text { end winding }}+L_{\sigma, \text { harmonics }}
$$

\section{Model Experimental Validation}

An experimental validation of a machine model whose main aim is the simulation of transient torques due to field harmonics constitutes a serious challenge. Since, as indicated in chapter I, from an operational and mathematical point of view there are no differences between three or 
multiphase machines as to the model structure and development (which applies to any number of stator or rotor phases), its validation has been carried out, for practical reasons, on a classical three-phase squirrel cage motor.

It is not at all unusual in papers which develop induction machine models including transient harmonic torques to resort almost exclusively to stator currents measurements in order to validate, via this indirect quantity, the simulated dynamic torques. However one can raise serious objections as to the reliability of a validation carried out this way. Indeed, in three phase induction motors, in clear contrast to what happens to the electromagnetic torque, the dynamic stator currents, in general, are scarcely modified by the field harmonics and, consequently, they are not a suitable quantity to validate the model as to its torque simulations.

As for direct torque measurements, strain gauges have been known for a long time.

Alternative and modern procedures resort to measure the shaft twist via optical or inductive methods. Magnetostrictive and magnetoelastic torque sensors are also two modern options based on the fact that the acting mechanical stress slightly modifies the magnetic behaviour of the shaft surface material. These sensors can be either integrated in the industrial application with a tailor made design (e. g. [11]) or coupled between load and motor shaft (e.g. [12]). We have explored this last way, but the results were unsatisfactory. The main reason for this, which applies to all of the above mentioned methods, lies in the fact that a well designed motor-to-load elastic coupling results in an important reduction of the first natural frequency of the whole system so that most of the quick oscillations present in the electromagnetic torque do not appear in the mechanical torque acting on the load shaft, which is the one actually measured by the torque sensor.

From Newton's law, the electromagnetic and shaft torques in the mechanical system of Fig. 1 always hold:

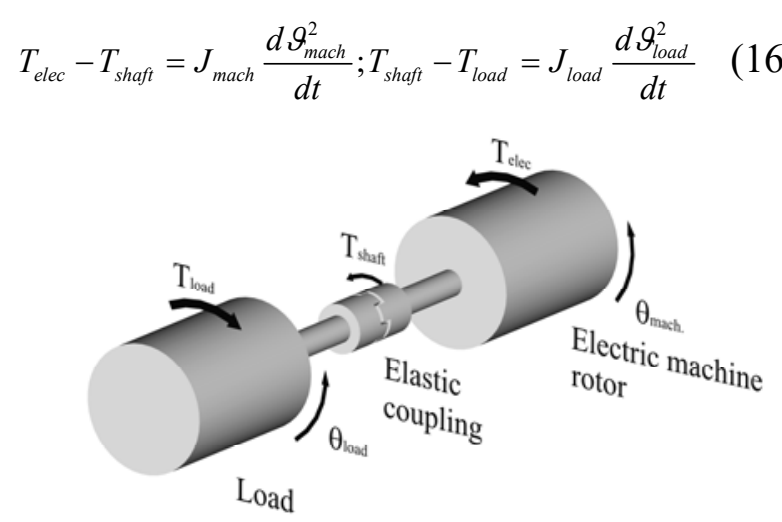

Fig.1 Elastically coupled motor rotor and load

Likewise, in the classical simplified approach, the shaft torque is related to the angular displacements at both ends of the elastic coupling ( $K$ and $\zeta$ being the elastic and friction parameters) by the equation:

$$
T_{\text {shaft }}=K\left(\vartheta_{\text {mach }}-\vartheta_{\text {load }}\right)+\zeta\left(\frac{d \vartheta_{\text {mach }}}{d t}-\frac{d \vartheta_{\text {mach }}}{d t}\right)
$$

One could think of using (17) combined with the general equation (16) to determine the electrical torque, but this is not feasible either. Indeed, in order to precisely determine the very quick air gap torque oscillations starting from the 
measured shaft torque (where they are scarcely present), a very high accuracy both in the coupling equations system and in the shaft torque measure is needed. However, first, for such purpose the actual behaviour of the elastic coupling can not at all be modelled as simply as in (17) (To this adds the important fact that it would be quite difficult to accurately estimate all the required mechanical parameters for the new and more precise equations set). And second, one has to keep in mind that industrial torque transducers usually lack the bandwidth required for the accurate measurement of torque oscillations of hundreds of Hz. This is so, simply because they do not need such a bandwidth for the typical industrial applications (elastic couplings are used just to prevent the high frequency components in air gap torque oscillations from appearing on the load shaft).

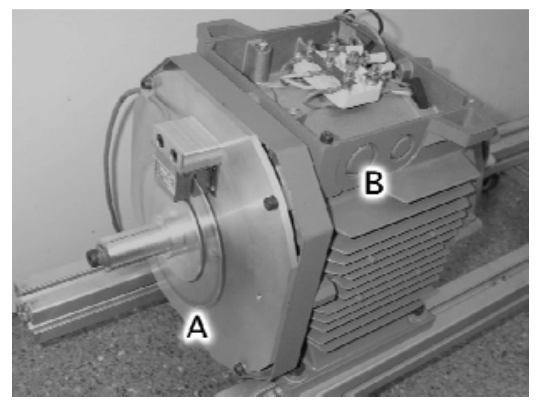

Fig.2 ACC3 Ferraris sensor (A) installed on uncoupled ABB motor (B)

In order to get rid of the main difficulties for measuring the air gap torque which are associated essentially to the motor-load coupling, very precise acceleration measurements in different no load direct-on-line start ups of the uncoupled motor (see Fig. 2) was the method chosen to validate the model. In these conditions, assuming the rotor as an ideal rigid body, electric torque has just to overcome the rotor inertia:

$T_{\text {elec }}=J_{\text {mach }} \frac{d \vartheta_{\text {mach }}^{2}}{d t}$

that is, torque equals acceleration to a given scale.

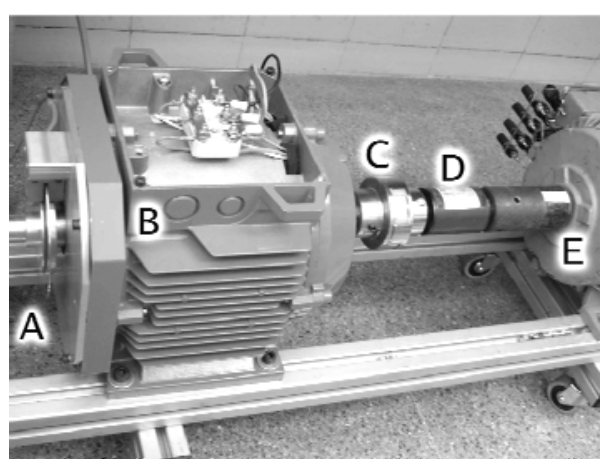

Fig. 3 ACC3 Ferraris sensor (A) installed on ABB motor (B) which is elastically coupled (C) to torque meter TH-HR-RD75 (D) and Auxiliary motor (E) in the workbench at Universidad Politécnica de Valencia

Being rigorous, in (18) a small loss torque (mechanical losses) should be taken into account. As these losses come primarily from the cooling fan, we removed it from the drive axis. Notice, on the other hand, that the no-load motor start up is really fast: at rated voltage a little more than $40 \mathrm{~ms}$ suffice to reach 1500 t.p.m. This demands a highly accurate estimation of the electric and mechanical model parameters because an almost perfect agreement between measured and calculated instantaneous rotor position is a must. Otherwise, even slight position errors result in important errors in the 
calculated torque for the higher harmonics which, in turn, increases the position errors.

Acceleration was measured with the high precision Hübner acceleration sensor ACC93 [13] (Fig. 2), based on the Ferraris principle [14]. The sensor was installed on the motor and calibrated in Hübner headquarters in Berlin [15] and then the set was sent back to the Universidad Politécnica de Valencia (UPV) in Spain.

The adequacy of the acceleration sensor was first analyzed by us by an independent test: a direct-on-line start up of an auxiliary motor elastically coupled (Fig. 3) to the main motor (open-circuited). The main motor rotor acceleration (Ferraris acceleration sensor) and the shaft torque (Magnetoelastic torque sensor) were simultaneously measured during the start up. In this test, under null main motor electric torque, the shaft torque measurement must reproduce, according to (16), the acceleration measurement to a given scale:

Tora $-T_{\text {shaft }}=J_{\text {mach }} \frac{d \vartheta_{\text {mach }}^{2}}{d t} \Rightarrow T_{\text {shaft }}=-J_{\text {mach }} \frac{d \vartheta_{\text {mach }}^{2}}{d t}$

This is just what can be observed in Fig. 4, which also highlights the limited bandwidth of the industrial torque transducer.

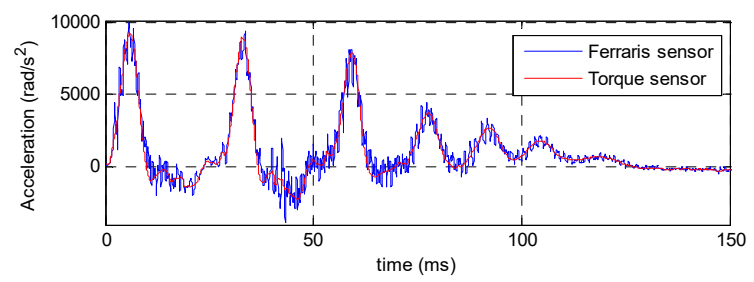

Fig. 4 Acceleration and shaft torque during a direct start-up of the auxiliary motor (main motor disconnected)

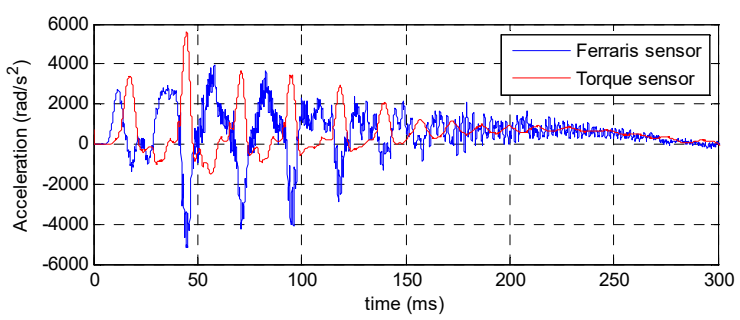

Fig. 5 Acceleration and shaft torque during a direct start-up of the main motor (auxiliary motor disconnected)

Fig. 5 shows the same measurements but during a direct-on-line start-up of the main motor (auxiliary motor disconnected now from the mains). Of course, in this case, and as predicted by theory (see again equation (16)), shaft torque and main rotor acceleration greatly differ from one another. This figure confirms how difficult it is to rebuild the airgap torque from the measurements of a shaft torque transducer, as already explained. Certainly, it would be possible to obtain the electric torque, whichever the particular conditions of the motor-load coupling and, moreover, during any steady or transient state, from simultaneous rotor acceleration and shaft torque measurements, provided both sensors have enough bandwidth, since as deduced from (16):

$T_{\text {elec }}=T_{\text {shaft }}+J_{\text {mach }} \frac{d \vartheta_{\text {mach }}^{2}}{d t}(20)$

However, to validate the model, the actual electric torque obtained this way has to be compared with the computed one. But to simulate the system formed by the motor coupled to a load it still would be necessary to know the equations of the elastic coupling. This is not so 
with the model validation method chosen in this paper.

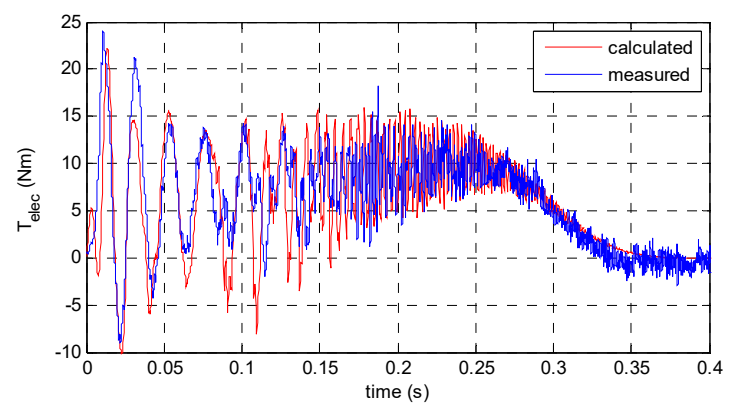

Fig. 6 Torque curves obtained by simulation and measured ( $40 \%$ of rated voltage) considering up to 55th harmonic

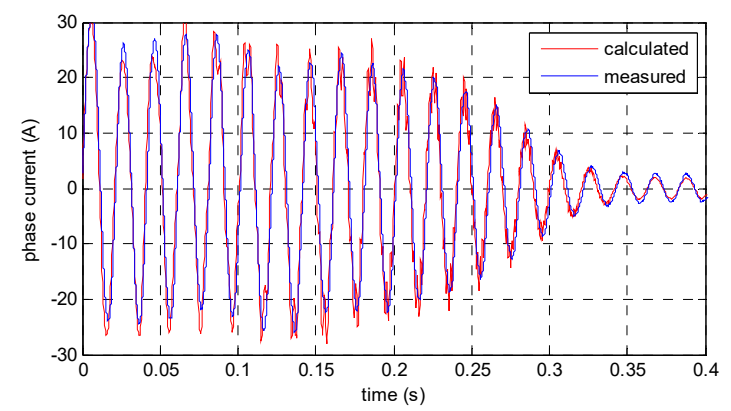

Fig. 7 Current curves obtained by simulation and measured ( $40 \%$ of rated voltage) considering up to 55th harmonic

The main data of the motor used for model validation can be found in Table 1. It is an ABB squirrel cage drive manufactured in ABB's Barcelona factory, which kindly provided all the documentation about constructive characteristics and the standard values of more than thirty electrical parameters. The values of those parameters needed for simulations were previously confirmed (with small discrepancies) in the electrical machines laboratory of the UPV.
In Fig. 6 to 9 (always star connection), results from simulations are compared with the ones obtained by direct measures from no load start ups under different stator voltages.

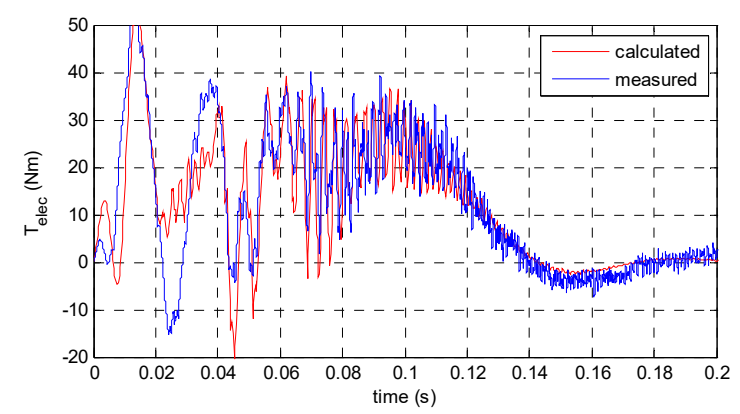

Fig. 8 Same as Fig. 6 but at $60 \%$ of rated voltage

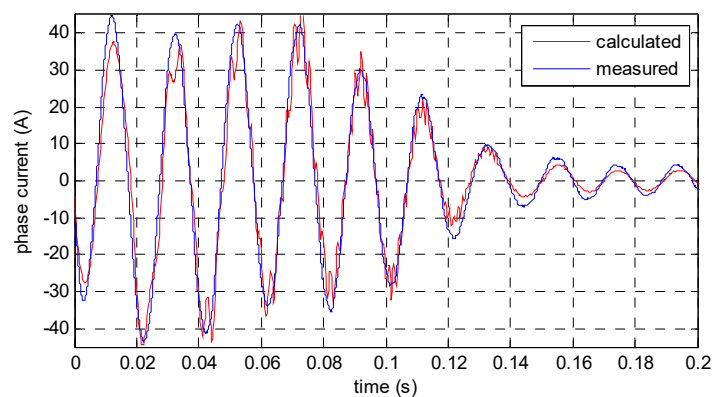

Fig. 9 Same as Fig. 7 but at $60 \%$ of rated voltage

Fig. 6 to 9 show a good agreement between measured and calculated torques for input voltages of up to $60 \%$ of the rated voltage (small or no saturation effect, as required by the model). The still remaining discrepancies are mainly due to the following reasons:

- Leakage induction values (very important in transient processes) cannot be measured in a highly accurate way.

- In addition to previous point, slot leakage inductances in the tested motor are reduced by some $45 \%$ with high currents at full voltage start up (This is an intentional design - in 
order to increase start up torque, as in small motors one can not make use of skin effect).

- The split of total flux linkages into common and leakage flux linkages is just a simplifying assumption as first approach to reality.

- Slotting effects have been taken into account only through the Carter's factor.

- Resistance values are not constant (conductors heating).

- Interbar currents have not been considered. (In some cases, especially in motors with skewed rotor bars, they have a relevant effect on the high order harmonic torques [16]).

- Rotor body, rotor axis and acceleration sensor are not an ideal rigid body.

- Perfect symmetry does not exist (e. g. some eccentricity level is unavoidable in any motor).

Table 1

Motor ABB M2AA 112 M-4 Main Parameters

\begin{tabular}{ll}
\hline \hline General & Un=400/230 V, In=8.6/ $15 \mathrm{~A}, \mathrm{f}=50 \mathrm{~Hz}, \mathrm{n}=1435 \mathrm{tpm}$, \\
& $\eta=84.5 \%, 4 \mathrm{~kW}$ \\
\hline Construc. & $\mathrm{D}=115 \mathrm{~mm}, \mathrm{l}=98 \mathrm{~mm}, \delta=0.4 \mathrm{~mm}, \mathrm{p}=2, \mathrm{~J}=0.015 \mathrm{Kg} \mathrm{m}^{2}$. \\
\hline Stator & 36 slots, $\mathrm{Z}=32$, full pitch coils, $\mathrm{L} \sigma, \mathrm{str}=6.07 \mathrm{mH}(3.57$ \\
& $\mathrm{mH}$ without harmonics effect $), \mathrm{R}=1.25 \Omega /$ phase, \\
\hline Rotor & 28 bars, $\mathrm{R}=0.07 \mathrm{~m} \Omega /$ Bar, L $\sigma$, bar $=0.52 \mu \mathrm{H}(0.28 \mu \mathrm{H}$ \\
& without harmonics effect $),$ mech. skewing $2,47^{\circ}, \mathrm{Alu}$ \\
& cage with closed slots \\
\hline \hline
\end{tabular}

\section{Main Impact of Field}

\section{Harmonics on Transient}

\section{Electromagnetic Torques .}

After getting a reasonable confidence in the model accuracy, a systematic plan of "computer tests" was carried out [17] to asses the influence of the field harmonics on the industrial motors electric transient torque. Despite the model being valid for an arbitrary number of rotor and stator phases, in a first stage of the study focus was set on three phase squirrel cage motors due to their relevance in industry applications. For that purpose 5 motors, identical to ABB motor but with different rotor bar numbers $(24,26,28,30$ and 32) were first analyzed.

The "tests" analyzed more exhaustively were direct-on-line start up tests (with different load torque, system inertia, initial rotor position as well as different amplitude, frequency and initial phase of the supply voltage). Each of these tests began with the same basic configuration of stator winding and then, besides the modifications above mentioned, changes in the winding pitch, slot skewing, slot opening, leakage inductances, number of harmonic considered and air gap width were also introduced. Other tests performed were: sudden change of motor load, unplugging, drop-outs and constant speed operation mode. In total more than 250 simulations have been carried out [17]. The following figures (always star connection and no rotor skewing to increase harmonic 
torques) show several examples of typical performance features that could always be observed, although to different extent depending on the particular motor design.

Fig. 10 shows that space harmonics, in general, scarcely influence stator currents of three phase squirrel cage motors, as clearly opposed to their influence on the torque (Fig. 11). Therefore, one should be very cautious with those motor models whose validation relies exclusively on current measures.
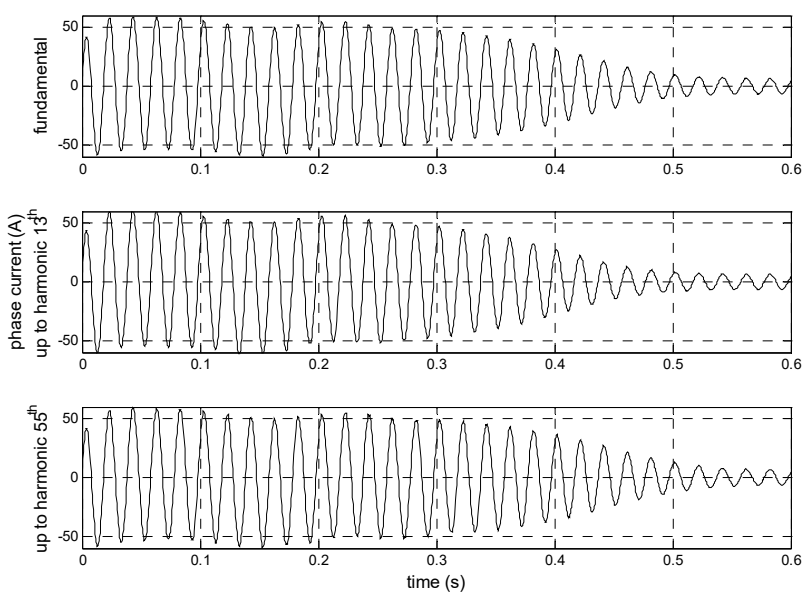

Fig. 10 Phase current calculated during direct start up taking into account only the fundamental space waves and up to harmonics 13th and 55th. $180 \mathrm{~V}, 24$ rotor bars, $\mathrm{T}_{\text {load }} 10 \mathrm{Nm}, \mathrm{J}_{\text {load }} 0,09$ $\mathrm{kg} \cdot \mathrm{m}^{2}$

On the other hand, from previous Figs. 6 and 8 also follow that space harmonics hardly influence at all the torque during the final stage of start-up transients. This is a particular example of a fact observed in all of the simulations: harmonic fields show a negligible effect on the torque at reduced instantaneous frequencies of the rotor currents (usually such operation states are associated to low slip operation modes). The following figures 12 to 15 confirm this general conclusion.
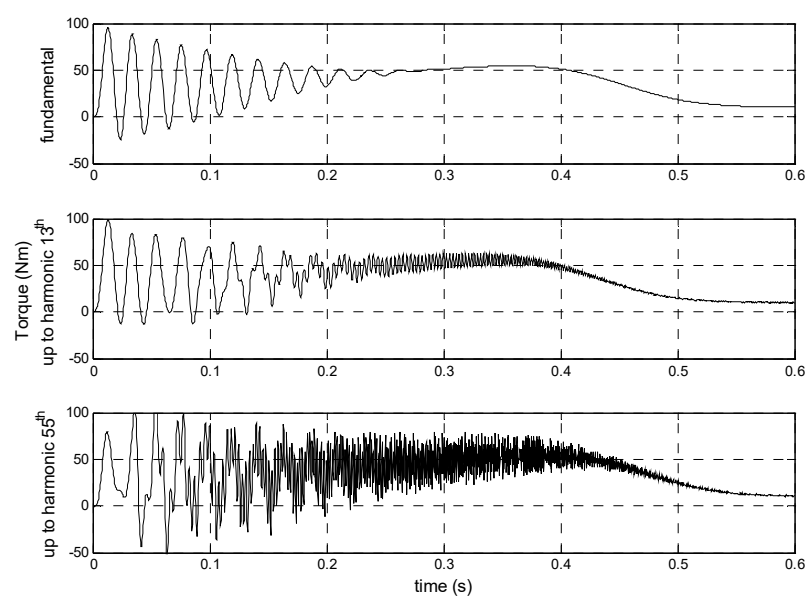

Fig. 11 Torque calculated during direct start up taking into account only the fundamental space waves and up to harmonics 13th and 55th. 180 $\mathrm{V}, 24$ rotor bars, Tload $10 \mathrm{Nm}, \mathrm{J}_{\text {load }} 0,09 \mathrm{~kg} \cdot \mathrm{m}^{2}$

Fig. 12 shows a sudden load change calculated with the fundamental space waves only and taking into account up to the $33^{\text {rd }}$ harmonic. One can realize that transient motor torque is not influenced by field harmonic as the whole transient evolves with small rotor current frequencies.

Figures 13 and 14 show a direct on-line start-up at a reduced and constant line frequency of $4 \mathrm{~Hz}$. The influence of field harmonics on the torque is negligible during the whole process $^{1}$, in

\footnotetext{
${ }^{1}$ Although in this example most of the start-up process at the constant frequency of $4 \mathrm{~Hz}$ takes place at large slips, the instantaneous frecuency of the main rotor currents are
} 
clear contrast to what happens at the usual line frequency of $50 \mathrm{~Hz}$ (Fig. 6, 8 and 11).

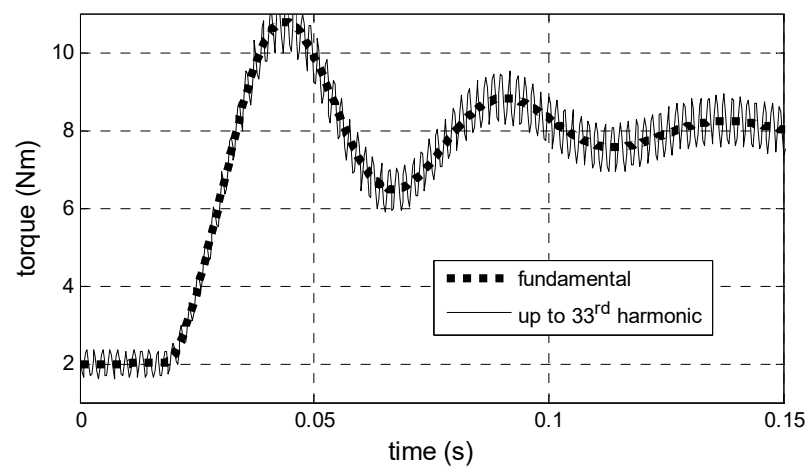

Fig. 12 Calculated torque during a sudden motor load change from 2 to $8 \mathrm{Nm}$. $170 \mathrm{~V}, 28$ rotor bars, $\mathrm{J}_{\text {load }} 0,0 \mathrm{~kg} \cdot \mathrm{m}^{2}$

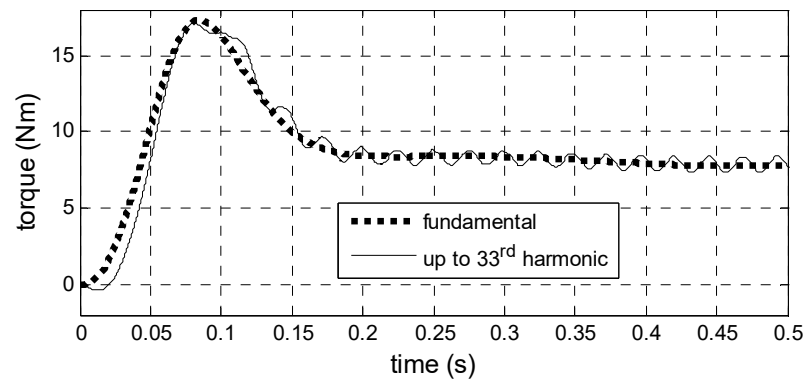

Fig. 13 Direct-on-line start-up at $20 \mathrm{~V}$ and $4 \mathrm{~Hz}$. Constant load torque of $8 \mathrm{Nm}, 28$ rotor bars

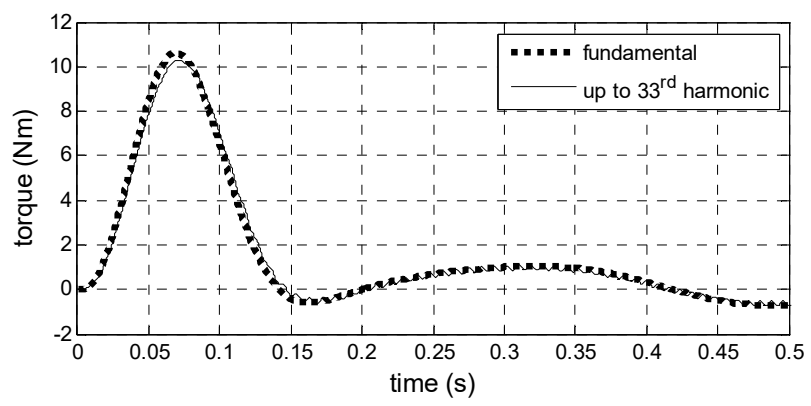

Fig. 14 As Fig. 13, but with null load torque

Finally, Fig. 15 shows the transient after a line dropout. In contrast to the two previous examples, there is now a heavy presence of very small all along the start-up, and this is the key point as to the influence of harmonic torques. harmonic torques. This is due to the fact that the instantaneous frequency of the rotor currents reaches almost half the rated stator frequency in this example. Of course, changing the conditions in a suitable manner (short dropout duration, big system inertia) would result in very small frequencies of the rotor currents after the dropout, and the simulations show again that, in such cases, the influence of the field harmonics on the torque is negligible.

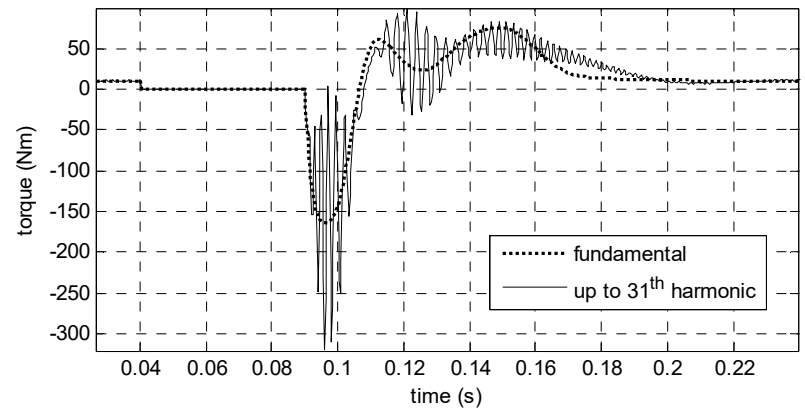

Fig. 15 Torque after a line dropout. Dropout duration $50 \mathrm{~ms}, 180 \mathrm{~V}, 30$ rotor bars, Tload 10 $\mathrm{Nm}, \mathrm{J}_{\text {load }} 0,02 \mathrm{~kg} \cdot \mathrm{m}^{2}$

In all the operational conditions shown in Figs. 11 to 14, as well as during the final stage of start-up transients in Figs. 6 and 8, the field harmonics effect on electromagnetic torque is negligible. So, it can be stated that electromechanical energy conversion in all these situations is almost exclusively due to the induction fundamental waves. It is worth mentioning that this fact does not mean, as often erroneously stated, that there are no field harmonics. The stator and rotor field harmonics are still present, but they can be assumed to be linked exclusively to their own winding and to produce leakage flux only. In other words, in 
such conditions the magnetic coupling statorrotor (and therefore, the electromechanical energy conversion) takes place only through the fundamental space waves.

\section{Analysis and physical explanation of the results in the previous chapter}

As just shown, as to the electric torque, field harmonics in three phase induction motors can play an important role only at high instantaneous frequencies of the rotor currents.

For a fast physical explanation of this fact, let us start from the simplified assumption that the flux level in the machine is nearly constant all along these different examples (Actually, in industrial applications of induction motors, the main flux level suffers significant changes only in rare situations, e. g., motor working in the field weakening region). At constant flux level, a high rotor frequency results in a large rotor e.m.f. and, consequently, large rotor currents and current sheet. As the machine flux stays close to constant, this implies a large stator current sheet and an increase in the angle between stator and rotor space current sheets (see Fig 16.)

Let us apply these conclusions more in detail for instance to any of the Figs. 6, 8. Assume, only for the sake of simplicity, a very slow starting process, and then let us study a time span so short we can accept speed is close to constant. According to (14), the torque produced by the interaction of harmonic stator and rotor field waves of the same order is always proportional to the vectorial product of their current space phasors. Therefore, since these stator and rotor field harmonics turn at different speeds, they produce a pulsating torque the amplitude of which is proportional to the product of the stator and rotor currents amplitudes. From zero up to pull-out torque speeds (high rotor frequencies), those currents are large and still larger is their product, but at standard steady state speeds (currents decrease by a factor around 5 in a standard 4 pole motor), this product may become up to 16 or 25 times smaller and so does as well their corresponding harmonic torque. That is, in the final stage of transients in Figs. 6 and 8 , torques due to field harmonics are negligible. On the contrary, stator and rotor current space phasors of the fundamental space waves turn at the same speed, and thus the constant angle between both phasors at each speed of the transient plays a fundamental role. At high rotor frequencies the sine of this angle has a very small value (Fig. 16), and the vectorial product of the phasors becomes small, even with large currents (as attests the small useful starting torque of single cage induction motors).

However, at small rotor frequencies, the angle sine greatly increases and the machine provides a comparatively large fundamental torque even though the currents have substantially diminished. 
This explanation also applies, of course, to transients in Figs. 13 and 14. These last two transients are characterized by small rotor frequencies all along the start-up. Therefore, pulsating harmonic torques do not play here any significant role: the calculated torque is almost the same no matter how many harmonics are taken into account. This is just the opposite to what happens during full mains frequency startups (Fig. 6, 8 and 11) when high rotor frequencies result in a strong influence of the pulsating harmonic torques.

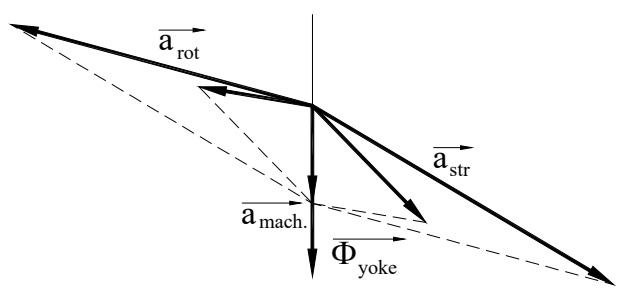

Fig. 16 Stator, rotor and machine current sheet space phasors at constant main flux level but with different frequencies of rotor currents

To sum up, the work in this paper has conceptually (physical explanation), experimentally (direct electromagnetic torque measurements) and through numerous simulations shown that, no matter the windings constitution, space harmonics influence on the torque in three phase motors is negligible at small rotor frequencies (low slip transients). This should be considered one of the main paper contributions. Therefore, when assessing the impact of space harmonics on the electromagnetic torque of three phase induction motors one has to clearly distinguish between converter-fed and mains fed motors. In the first case (always low slip transients), all of the space harmonics can be neglected. The relevance of this conclusion is further enhanced when taking into account that, as it is well known, the space harmonics in multiphase machines can be grouped into various independent families (for three phase star windings all of the harmonics belong to the same family). Therefore, the above mentioned conclusion can be easily extended to each independent family, which means that, in converter-fed multiphase induction motors only the space harmonics which are head members of their groups need to be considered in the control equations, since they alone are able to provide a useful torque contribution.

In the second case, that is, in the case of three phase motors connected to the mains, space harmonics may have an important impact on the transient air gap torque. Here, the simulations show that the particular motor design (stator and rotor slots number, winding pitch, slot skewing, slot opening, etc) plays a crucial role. Of course, also to these cases applies the rule that space harmonic effects can only be significant during high slip transients. Unfortunately there is one of such transients which is unavoidable and very important: motor starting up. It is well known that due to harmful synchronous and asynchronous harmonic torques certain motors may experience cogging or crawling. The analysis of these problems is not the subject of this paper. They have been extensively dealt with 
e. g., in [18] where practical information on saturation and motor-load coupling effects has been included too. It should be added for the sake of completeness that in some motors the mentioned problems are significantly increased when using delta connection and /or parallel winding branches [19].

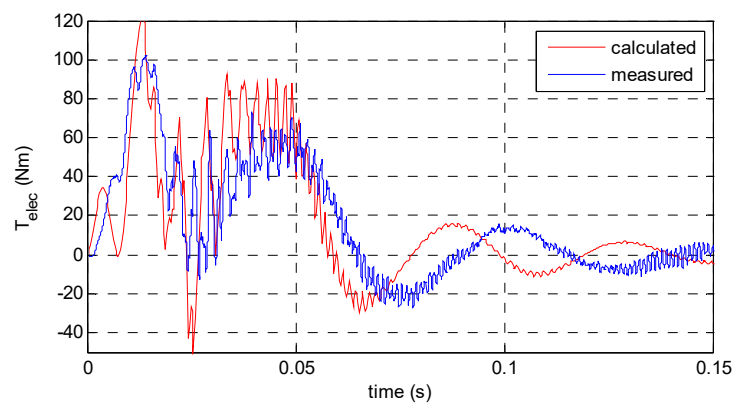

Fig. 17 Same as Fig. 6 but at $80 \%$ of rated voltage

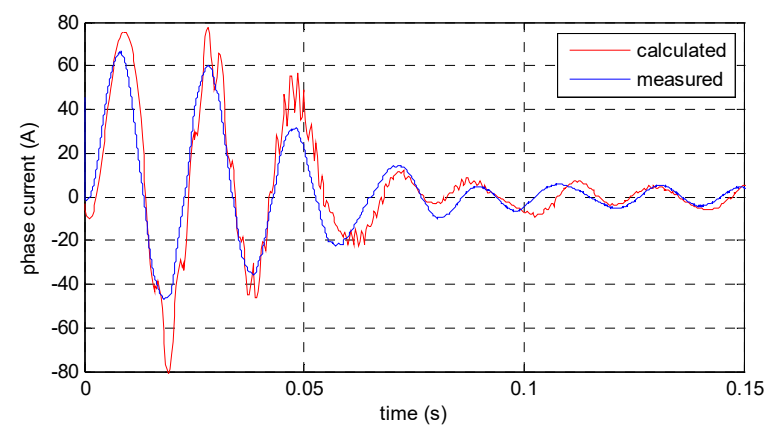

Fig. 18 Same as Fig. 7 but at $80 \%$ of rated voltage

The limitations of the model were stated at the beginning of section II. The main one is related to the saturation effects. However, saturation does certainly affect the actual torque values but does not invalidate the main conclusions of this work, as one can observe from Figs. 17 and 18, taken at $80 \%$ of rated motor voltage. At this saturation level the differences between calculated and measured torque due to the model limitations become evident: while the torque and currents are calculated using constant main and leakage flux inductances, the leakage and main magnetic circuit saturation level in the motor actually changes all along the start-up and, therefore, the corresponding inductances change continuously as well. Consequently, it is impossible for a model with constant parameters, to adjust its simulation results to the experimental ones all along the start-up transient. However, as in the simulations and measures with no saturation, here too the main impact of the space harmonics on the torque appears in the high slip stage of the transient. Their impact on the currents are scarcely relevant. Notice too that even under saturation the model accuracy as to the currents is very acceptable.

\section{Conclusions}

A dynamic model for induction motors with arbitrary number of phases, taking into account the space harmonics and valid for arbitrary voltage waveforms has been developed using space phasors. The problem of a reliable experimental model validation as to the torque simulations has been thoroughly discussed. The solution chosen has been to carry out very accurate acceleration measures during no load direct-on-line starting ups at different supply voltages. Electromagnetic torque and current measures and simulations show a good agreement in low or no saturation regions 
After model validation, more than 250 simulations were carried out in order to assess space harmonics effects on transient torque of three phase squirrel cage motors. The simulations were performed on five different motors under clearly distinct operating conditions. Moreover, for each motor, various design changes (slot skewing, winding pitch, air gap width , etc...) were systematically introduced for the simulations.

The main result of this study is that in three phase squirrel cage motors, space harmonics may certainly have an important impact (which crucially depends on the motor design) on the transient electromagnetic torque. However, this impact can be significant only in high slip transients, that is, in motors with direct connection to the mains and during processes like start up, unplugging, drop out, injection braking, etc. Therefore, and by contrast, in converter fed three phase induction motors, the field harmonics effect on electromagnetic torque is negligible, no matter the winding structure. This statement has also been explained and justified from a physical perspective.

\section{Appendix}

\section{A.1 Space phasor concept}

The steady state values of the main quantities (currents, voltages etc...) of many electrical circuits often vary sinusoidally in time. These values can be determined by means of the projection of a rotating oriented segment in the complex plane (time phasor). This symbolical representation method is in worldwide use.

Unlike circuits, in the study of electrical machines it is necessary to operate with certain quantities which are spatially distributed (current sheet, induction, etc). Space phasors are very suitable to this task. By definition a space phasor is an oriented segment in the complex plane that characterizes at every moment the spatial sinusoidal distribution of an internal machine quantity. The phasor always points to the positive maximum of the wave (in the case of bipolar waves) and its modulus is equal to the wave's amplitude. Both the wave amplitude and speed may vary in an arbitrary manner.

Usually the internal quantity is not bipolar or not sinusoidal. In the last case we proceed to its Fourier expansion and assign to each space harmonic its corresponding harmonic space phasor. To this end we define a domain transformation in such a manner that any angle, $\alpha$, in the machine domain becomes an angle $v \alpha(v$ $=$ absolute harmonic order) in the phasorial domain (Fig. 19). Notice that in this way every multipolar wave is characterized by just one phasor (the same coordinate in the phasorial domain corresponds to all its positive crests in the machine). Notice too that this transformation has been actually used by electrical engineers for more than a century, since it boils down to transform the mechanical angles into electrical ones. 


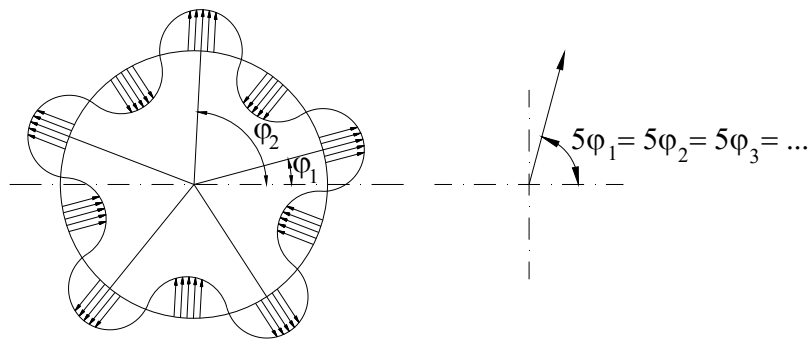

Fig. 19 Space wave of five pole pairs. Representation in the machine (left) and in the phasorial domain (right)

\section{A.2 Space phasor formulae of general validity}

Choosing the conductor as the basic winding unit to determine the airgap field was first proposed in [20]. The advantages of such idea (e.g., arbitrarily complex windings layouts can be very easily modelled) were later underlined in [21,22]. The procedure has also been used by other authors (e, g. [23])

The Fourier expansion of the current sheet (linear current density), $\mathrm{A}_{\mathrm{a}}(\alpha, \mathrm{t})$, produced by one conductor "a" of width $\Delta$ (Fig. 20) carrying an arbitrary current, $\mathrm{i}_{a}(\mathrm{t})$ is given by $[21,22]$ $A_{a}(\alpha, t)=\frac{i_{a}(t)}{\pi D}+\frac{2 i_{a}(t)}{\pi D} \sum_{v=1}^{\infty} \frac{\sin v \frac{\Delta}{2}}{v \frac{\Delta}{2}} \cos v\left(\alpha-\alpha_{a}\right)$
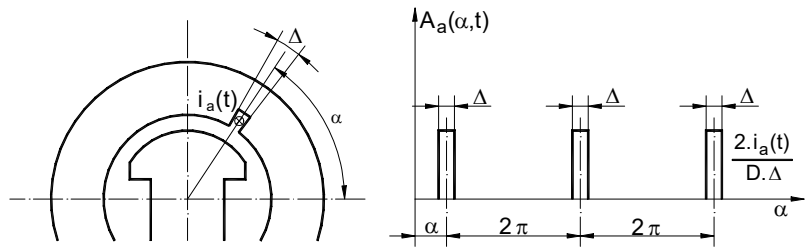

Fig. 20 Current sheet space wave produced by an axial conductor

From (A.1) it follows that the space phasor of the current sheet harmonic of absolute order $v$ produced by the conductor "a", $\mathbf{a}_{\mathbf{v}, \mathbf{a}}$ is given by: $\overrightarrow{a_{v, a}}=\frac{2 i_{a}(t)}{\pi D} \frac{\sin v \frac{\Delta}{2}}{v \frac{\Delta}{2}} e^{j v \alpha_{a}}=\frac{2 i_{a}(t)}{\pi D} \xi_{v, s l o t} e^{j v \alpha_{a}}$

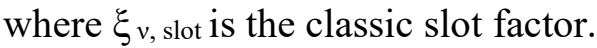

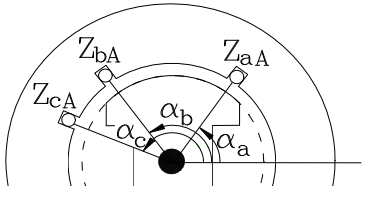

Fig. 21 Phase A with with $Z_{\mathrm{aA}}$ conductors at $\alpha_{\mathrm{a}}, \mathrm{Z}_{\mathrm{bA}}$ conductors at $\alpha_{\mathrm{b}}$, etc,

For a whole phase A, with an arbitrary distribution of its conductors (Fig. 21), the space phasor of its current sheet harmonic of absolute $\operatorname{order} v($ relative order $h=v / p)$ is obtained by simply adding the space phasors of all of its conductors. Applying (A.2), we get:

$$
\begin{aligned}
& \overrightarrow{a_{v, A}}=Z_{a, A} \overrightarrow{a_{v, a}}+Z_{b, A} \overrightarrow{a_{v, b}}+\ldots . .= \\
& =\frac{2 i_{A}(t)}{\pi D} Z_{A} \xi_{s l o t, v} \frac{Z_{a, A} e^{j v \alpha_{a}} \pm Z_{b, A} e^{j v \alpha_{a}} \pm \ldots \ldots . .}{Z_{A}}= \\
& =\frac{2 i_{A}(t)}{\pi D} Z_{A} \overline{\xi_{v, A}}
\end{aligned}
$$

The complex number $\xi_{\mathbf{v}, \mathbf{A}}$ in (A.3), also often written $\xi_{\text {hp,A }}$

$$
\overline{\xi_{v, A}}=\overline{\xi_{h p, A}}=\xi_{\text {slot, },} \frac{Z_{a, A} e^{j v \alpha_{a}} \pm Z_{b, A} e^{j v \alpha_{a}} \pm \ldots \ldots}{Z_{A}}
$$

is called the complex winding factor of absolute order $v$ of phase A [23]. The sign \pm in (A.4) depends on the current direction in the conductors. For low order space harmonics (which are, by far, the most important ones), the slot factor $\xi_{v \text {,slot }}$ is always very close to 1 , so that usually (A.4) simplifies to

$$
\overline{\xi_{v, A}}=\overline{\xi_{h p, A}}=\frac{Z_{a, A} e^{j v \alpha_{a}} \pm Z_{b, A} e^{j v \alpha_{a}} \pm \ldots \ldots .}{Z_{A}}
$$

Of course, if wanted, one can always make use of the exact relationship (A.4) instead 
of (A.5) (Actually, this has been the option chosen in this paper). Notice that the distribution of the phase A conductors may be arbitrarily complicated. However, once the phase structure is known, its complex winding factors (modulus and argument) are obtained in a fast and easy manner. In symmetrical windings one can easily check that the modulus of $\xi_{h p}$ equals that of the classic winding factor for the harmonic of relative order $h$.

The $v$ current-sheet space phasor produced by a polyphase winding of arbitrary structure equals the sum of the space phasors of al its individual phases A, B, C...

$\overrightarrow{a_{v, \text { wind }}}=\overrightarrow{a_{v, A}}+\overrightarrow{a_{v, B}}+\overrightarrow{a_{v, C}}+\ldots$

For the particular case of a m-phase symmetrical winding with arbitrary currents, (A.6) becomes equation (3) in this paper.

It must be underlined that equations (A.3) to (A.6) always hold no matter the phase structure, the number of space harmonics considered, the rotor shape or whether the magnetic circuit be saturated or not.

Fig. 22 depicts the yoke flux produced by a bipolar magnetic induction wave sinusoidally distributed along the inner stator surface. The rotor shape may be arbitrary (a salient pole structure has been drawn in Fig. 22). A simple calculation leads to the following equation describing the relationship between the space phasors of the yoke flux and induction waves $\overrightarrow{\Phi_{1, y o k e}}=\frac{l D}{2} B_{1}(t) e^{j \alpha_{1}(t)}=\frac{l D}{2} \overrightarrow{B_{1}} e^{-j \pi / 2}$ where $B_{1}(t)$ is the amplitude of the stator induction wave at instant $\mathrm{t}$. Angle $\alpha_{1}(\mathrm{t})$ defines the instantaneous position of the yoke flux wave maximum. Amplitude and positions of the waves may vary in an arbitrary manner. Notice that the stator yoke flux at any $\alpha$ (at any yoke section specified by $\alpha$ ) in Fig. 22 is simply the projection of the yoke flux space phasor over the radius defined by $\alpha$, that is

$$
\Phi_{1, \text { yoke }}(\alpha, t)=\operatorname{Re} a l\left[\overrightarrow{\Phi_{1, \text { yoke }}} e^{-j \alpha}\right]=\frac{l D}{2} B_{1}(t) \cos \left[\alpha_{1}(t)-\alpha\right]
$$

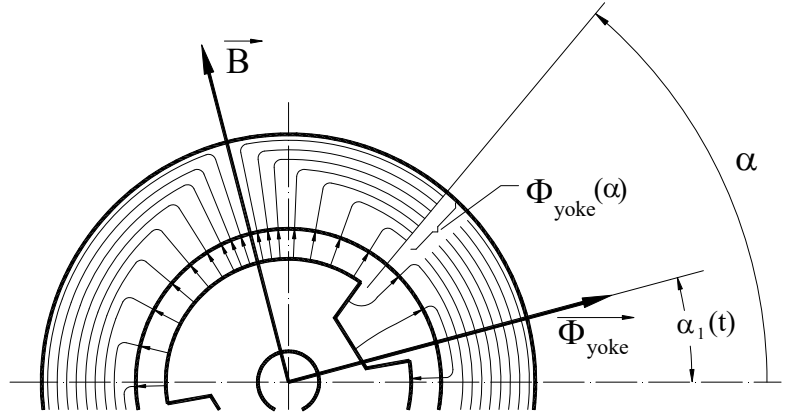

Fig. 22 Stator yoke flux and magnetic induction (in the stator inner surface) space waves. Both waves (and their corresponding space phasors) are in space quadrature

Notice that a sinusoidal stator induction wave always results in a sinusoidal yoke flux wave with the same pole number, no matter the rotor shape. For multipolar waves, (A.7) and (A.8) become:

$$
\begin{aligned}
& \overrightarrow{\Phi_{v, \text { voke }}}=\frac{D l}{2 v} B_{v}(t) e^{j v \alpha_{v}(t)}=\frac{D l}{2 v} \overrightarrow{B_{v}} e^{-j \pi / 2} \\
& \Phi_{v, \text { voke }}(\alpha, t)=\operatorname{Real}\left[\overline{\Phi_{v, \text { yoke }}} e^{-j v \alpha_{v}}\right]= \\
& =\frac{D l}{2 v} B_{v}(t) \cos v\left[\alpha_{v}(t)-\alpha\right]
\end{aligned}
$$

The air gap flux linkage of an arbitrary stator coil with negligible width, $\Delta$, can be calculated by replacing the coil by two equivalent annular coils of negligible $\Delta$, and 
summing up the yoke fluxes that crosses them (Fig. 23).
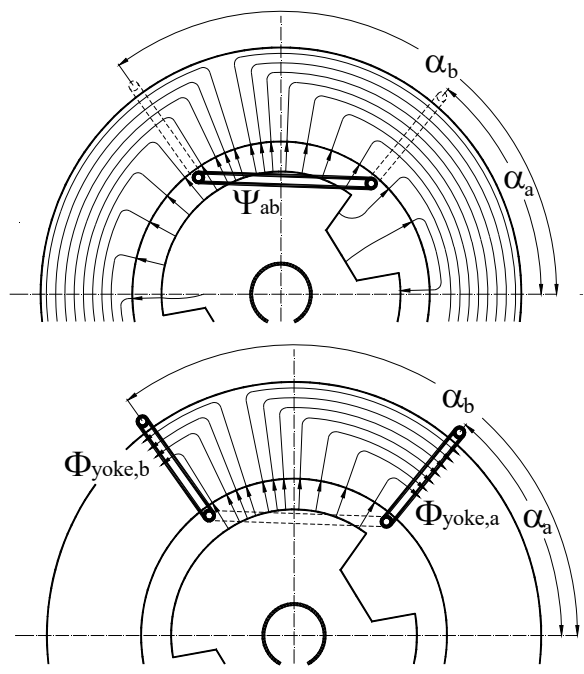

Fig. 23 Flux linkage of an arbitrary stator coil (above) can be calculated by replacing it by two equivalent annular coils (below) and summing up the yoke fluxes that crosses them

This process can be easily extended to all of the phase coils. Therefore, the flux linkages of a phase, A, with an arbitrary conductor distribution (Fig. 22) due exclusively to the yoke flux wave of order $v(v=h p)$ is obtained by simply summing up the values of the yoke flux at the yoke sections corresponding to each one of its conductors.

$$
\begin{aligned}
& \Psi_{\boldsymbol{v}, A}(t)=\sum_{x=a, b, c \ldots .} \pm Z_{x, A} \boldsymbol{\Phi}_{\boldsymbol{v}, \text { voke }}\left(\boldsymbol{\alpha}_{x,} t\right)= \\
& =\sum_{x=a, b, \ldots \ldots} \operatorname{Real}\left[ \pm Z_{x, A} \widehat{\boldsymbol{\Phi}_{\boldsymbol{v}, \text { yoke }}} e^{-j v \boldsymbol{\alpha}_{x}}\right]= \\
& =\operatorname{Real}\left[Z_{A} \overrightarrow{\Phi_{\boldsymbol{v}, \text { yoke }}} \frac{ \pm Z_{a A} e^{-j v \alpha_{a}} \pm Z_{b A} e^{-j v \alpha_{b}} \pm \ldots}{Z_{A}}\right]
\end{aligned}
$$

Taking into account (A.5) we get:

$$
\Psi_{v, A}(t)=Z_{A} \operatorname{Re} a l\left[\overline{\Phi_{v, \text { yoke }}} \overline{\xi_{v, A}^{*}}\right]
$$

where $\xi^{*}$ stands for conjugate complex of the complex winding factor $\xi$. (If the width $\Delta$ is to be taken into account, (A.12) remains valid by simply using (A.4) for $\xi$, instead of (A.5), as commented above).

The total air gap flux linkages of phase A (all air gap waves considered) become

$\Psi_{A}(t)=Z_{A} \sum_{v} \operatorname{Re} a l\left[\overrightarrow{\Phi_{v}} \overrightarrow{\xi_{v, A}^{*}}\right]$ (A.13)

Notice that, again, and like equations (A.3) to (A.6), equations (A.7) to (A.13) always hold too, no matter the rotor shape or whether the magnetic circuit be saturated or not.

\section{A.3 Space phasors formulae restricted to induction machines. Self and mutual inductances}

Contrary to the general equations (A.3) to (A.13), the relationship between current sheet and yoke flux waves changes for every different machine type and, for some machines, it may turn out to be very complex. However, for induction machines, and assuming the two classic hypotheses of ideal magnetic circuit and constant air gap of negligible width, $\delta$, the solution is quite simple. In such a case, any sinusoidal stator or rotor current sheet wave results in a yoke flux wave with the same pole number. The relationship between these waves or between their corresponding space phasors results, using basic magnetic laws, in:

$\overrightarrow{\Phi_{h p, y o k e}}=\frac{\mu_{0} l D^{2}}{4 \delta(h p)^{2}} \overrightarrow{a_{h p}}$

The current sheet phasor of absolute order $v=h p$ of the whole machine equals the sum of the stator and rotor current sheet phasors in a 
common phasorial reference frame. Using, for instance, the stator reference frame, one gets:

$\overrightarrow{a_{h p, \text { mach }}}=\overrightarrow{a_{h p, s t r}}+\left(\overrightarrow{a_{h p, r o t}}\right) e^{j h p \lambda(t)}$

where $\lambda$ is the instantaneous mechanical angle between stator and rotor. Notice that the phases may have an arbitrary distribution of conductors. For the particular case of symmetrical windings, (A.15) becomes equation (6) in the paper.

From (A.14) and (A.3), the instantaneous yoke flux wave of order $v$ produced by a phase A of arbitrary constitution is given by

$\overrightarrow{\Phi_{h p, A}}=\frac{\mu_{0} l D}{4 \pi \delta(h p)^{2}} i_{A}(t) \overline{\xi_{h p, A}}$

From (A.16) and (A.12), the airgap flux linkages of phase A due to the airgap induction wave of order $v$ produced exclusively by phase current $\mathrm{i}_{\mathrm{A}}(\mathrm{t})$ become

$$
\left[\Psi_{h p, A}(t)\right]_{i_{A}(t)}=\frac{\mu_{0} l D}{2 \pi \delta}\left(\frac{Z_{A}\left|\overline{\xi_{h p, A}}\right|}{h p}\right)^{2} i_{A}(t)
$$

Therefore, the airgap or the magnetizing self-inductance of phase A for the induction air gap wave of order hp becomes:

$$
L_{A A, h}=\frac{\mu_{0} l D}{2 \pi \delta}\left(\frac{Z_{A}\left|\overline{\xi_{h p, A}}\right|}{h p}\right)^{2}
$$

From (A.16) and (A.12) it also follows immediately that the airgap mutual inductance between two arbitrary phases A and B for the induction wave of order $\mathrm{hp}$ is :

$$
\begin{aligned}
& L_{A B, h}= \\
& =\frac{\mu_{0} l D}{2 \pi \delta} \frac{Z_{A}\left|\overline{\xi_{h p, A}}\right| Z_{B}\left|\overline{\xi_{h p, B}}\right|}{(h p)^{2}} \cos \left(\arg \overline{\xi_{h p, A}}-\arg \overline{\xi_{h p, B}}\right)
\end{aligned}
$$

where "arg" stands for argument. Equation (A.19) shows that the mutual inductance between two phases depends on the angle between the magnetic axes of both phases. Should this angle change along time ( one phase placed on the stator and the other one on the rotor) the mutual inductance changes accordingly. Notice that (A.18) and (A.19) apply to phases with arbitrary conductors distributions (in other words, they are also highly suitable, for instance, to the analysis of machines with stator or rotor faults, such as inter-turn short circuits or broken bars). .

Making use successively of equations (A.3), (A.6), (A.15) and (A.14) particularized to the case of symmetrical polyphase windings in stator and rotor with arbitrary phase currents, and taking into account (A.18) and (A.19), equation (A.12) becomes equation (7) in this paper (for a stator phase) or equation (8) for a rotor phase.

\section{References}

[1] D. White, H. Woodson, Electromechanical Energy Conversion. John Wiley \& Sons, 1959.

[2] F. Taegen, E. Hommes, Das allgemeine Gleichungssystem des Käfigläufermotors unter Berücksichtigung der Oberfelder. Teil I and II: in Archiv für Elektrotechnik, 55, (1972), pp. 21 - 31 and pp. $98-105$.

[3] F.S.Van derMerwe, The analysis of an Electric Machine with a Smooth Air-Gap Allowing for all Winding MMF Harmonics. Parts I and II Archiv für Elektrotechnik, 58, (1976) pp. 283-292 and 293-303

[4] H. R. Fudeh, C. M. Ong, Modeling and Analysis of Induction Machines Containing Space Harmonics Parts I, II and III: IEEE Transactions on Power 
Apparatus and Systems, Vol. PAS-102, No. 8, August 1983., pp. 2608 - 2615; 2616 - 2620; 2621 - 2628

[5] E. Hommes, G. C. Paap, The analysis of the 3-phase squirrel cage induction motor with space harmonics. Part 1 and 2: in Archiv für Elektrotechnik, 67, (1984) pp. 217-226 and pp. 227-236.

[6] B. Heller, V. Hamata, Harmonic Field Effects in Induction Machines. Elsevier Scientific Publishing Co. 1977.

[7] H. O. Seinsch. Oberfelderscheinungen in Drehfeldmaschinen. B.G. Teubner, Suttgart, 1992

[8] K. Oberretl, Losses, torques and magnetic noise in induction motors with static converter supply, taking multiple armature reaction and slot opening into account in IET Elec. Power Appl. (2007) pp. 517-531

[9] E. Levi, R. Bojoi, F. Profumo, H. A. Tolyat, S. Williamson, Multiphase induction motor drives. A technology status review in IET Electric Power Applications, Vol. 1 (2007) issue 4, pp. 489-516.

[10] R. H. Park, Two-Reaction theory of synchronous machines in A.I.E.E. Transactions, Vol. 48, p. 716-730 1929 and Vol. 52, p. 352-355, 1933.

[11] C. Wallin, H. Ling, A. Rasool Evaluation of torque pulses in industrial applications using the torque sensor Torductor-s presented at Sensor for Industry conference, 2001. Illinois USA.

[12] NCTE, High Dynamic, Non Contact, Rotary Torque Sensor - Series 2000 in http://www.ncte.de/ncte/ cms/front_content.php?idcat=27, 2011

[13] Hübner Berlin. Acc. sensor ACC93, Preliminary leaflet, 2002.

[14] A. Denne, H. Rausch, W. Freise, Aufnehmer zur Messung schnell veränderlicher Drehbeschleunigungen und Drehmomente in TechnischesMessen-tm, vol. 48, pp.339-42, October, 1981.

[15] L. Hillner, Hübner Berlin. Notes about ACC93 installation in motor ABB M2AA112 M-4 from Universidad Politecnica de Valencia. 2002.

[16] L. Serrano-Iribarnegaray, J. Martínez-Román, Critical review of the analytical approaches accounting for interbar currents and experimental study of ageing in two-speed asynchr. motors for elevator drives in IEE Proc. Elec Pow Appl. Vol. 152, (2005), pp. $72-80$.

[17] J. A. Echeverría-Villar, Aplicación de la teoría de los fasores espaciales al estudio de los campos armónicos en los regímenes transitorios de las máquinas asíncronas y sus repercusiones en los pares pulsantes. PhD Th.; Universidad Politécnica de Valencia, 2004.

[18] K.Oberretl, Parasitäre synchrone Dreh- und Pendelmomente in Asynchronmotoren. Einfluss von Ausgleichsvorgängen und Eisensättigung. Parts I and II in Archiv für Elektrotechnik, 77 (1994), pp. 179 190 and $277-288$.

[19] K.Oberretl, Ueber den Einfluss von parallelen Wicklungszweigen, Dreieckschaltung, Spulensehnung, Nutzschlitzbreite und Nutenschrägung auf das Drehmoment von Käfigläufermotoren in ETZ-A Bd. 86,1965 , p. 619-627.

[20] R. Brüderlin, Ueber eine graphische Zerlegung der Feld-Erregerkurve einer unregelmässigen Mehrphasenwicklung in ihre Einzelwellen in ETZ-Archiv für Elektrotechnik, 42 (1921), pp. 1093-1096.

[21] G. Köhler, A. Walther, Fouriersche Analyse von Funktionen mit Sprüngen, Ëcken und änlichen Besonderheiten in Archiv für Elektrotechnik, 25 (1931), pp. $747-755$.

[22] F. Lax, H. Jordan, Über die Fourier-Entwicklung der Felderregerkurve von schrittverkürzen Drehstromwicklungen beliebiger Phasenzhal in Archiv für Elektrotechnik, 34, H. 10, (1940), pp. 591 - 597.

[23] J. Stepina, Einführung in die allgemeine Raumzeiger Theorie der elektrischen Maschinen. Press of University of Kaiserslautern, 1979. 